\title{
FORMAÇÃO DE PROFESSORES E "ESCOLA ATIVA": REFLEXÕES EM TORNO DE UMA “TRADIÇÃO DE INOVAÇÃO”
}

\author{
Joaquim Pintassilgo ${ }^{1}$ \\ Lénia Pedro ${ }^{2}$ \\ Universidade de Lisboa
}

\begin{abstract}
RESUMO
O presente artigo tem como objetivo refletir sobre o conteúdo e implementação de duas disciplinas do currículo das Escolas do Magistério Primário portuguesas (antigas Escolas Normais Primárias), a Pedagogia e Didática Geral e a Didática Especial, tal como se expressam após a reabertura das referidas escolas, em 1942, e da definição dos novos programas no ano seguinte. As renovadas Escolas do Magistério Primário dão conta do esforço do Estado Novo salazarista para possuir, finalmente, escolas de formação de professores, no caso do chamado ensino primário, mais ajustadas às finalidades do regime autoritário português. Mas esse enquadramento não deixa de conviver, de alguma maneira, com uma tradição pedagógica, que mergulha as suas raízes na Escola Nova, agora adaptada aos novos tempos católicos e conservadores.

Palavras-chave: Formação de professores; Pedagogia; Didática; Escola Ativa; Tradição.

\section{TEACHER EDUCATION AND "ACTIVE SCHOOL": REFLECTIONS AROUND A "TRADITION OF INNOVATION"}

\begin{abstract}
This article aims to reflect on the content and implementation of two subjects in the curriculum of teacher education schools (ancient normal schools), Pedagogy and General Didactics and Special Didactics, as expressed after the reopening of those schools in 1942, and the definition of new programs next year. The renewed teacher education schools express the will of Salazar's New State to have, finally, teacher education schools, in the case of so-called primary education, more suited to the purposes of the Portuguese authoritarian regime. But this framework does not cease to live, somehow, with an educational tradition that has its roots in the so-called New Education, now adapted to the new Catholics and conservative times.
\end{abstract}

Keywords: Teacher education; Pedagogy; Didactics; Active school; Tradition.

No currículo das Escolas do Magistério Primário, tal como vigorou entre os anos 40 e 60 do século XX, tanto a Pedagogia como, em particular, as Didáticas, herdeiras do projeto de construção de uma ciência da educação, tornam-se o espaço curricular de eleição para a miscigenação de tradições pedagógicas e uma espécie de refúgio para a chamada Escola Ativa, com os seus autores internacionais de referência e os seus procedimentos pedagógico-didáticos. Mas elas são, também, nas suas duas vertentes, um espaço de identidade profissional para uma dada geração de formadores de professores que se revêm nesse discurso técnico-científico sem porem em causa a doutrina conservadora subjacente ao novo projeto de formação. Para além dos planos de estudo e programas, teremos em conta, muito especialmente, os compêndios produzidos para apoio às disciplinas e procuraremos, tomando a Escola do Magistério Primário de Lisboa como exemplo e a documentação do seu arquivo como suporte, verificar quem eram os seus 
professores e, na medida do que for possível, aproximar-nos da forma como geriam esses espaços curriculares ${ }^{3}$.

\section{Breve enquadramento histórico da Escola Superior de Educação de Lisboa}

A atual Escola Superior de Educação de Lisboa tem nas suas origens um conjunto de instituições que se dedicaram, desde a segunda metade do século XIX, à formação de professores. Em 1862 é inaugurada, em Marvila (Lisboa), a Escola Normal Primária para o sexo masculino logo seguida, em 1866, pela sua congénere para o sexo feminino, estabelecida no Calvário (também em Lisboa). No ano de 1914 inicia-se o regime de coeducação, com a integração das duas instituições no edifício do Calvário, processo que se consolidará, mais tarde, com a fusão das duas Escolas Normais Primárias num novo edifício, construído de raiz na Quinta de Marrocos em Benfica, inaugurado no ano letivo de 1918-1919. Em 1930, já em plena Ditadura Militar, as Escolas Normais passam a ser designadas por Escolas do Magistério Primário. Em 1936 são suspensas as matrículas, voltando a Escola a admitir novos alunos somente seis anos depois, quando já se começava a verificar uma carência de novos professores. A designação irá manter-se nas décadas subsequentes, até ao ano de 1986, aquando da criação da Escola Superior de Educação de Lisboa (NÓVOA, 1987; PINTASSILGO \& SERRAZINA, 2009; PINTASSILGO, MOGARRO \& HENRIQUES, 2010).

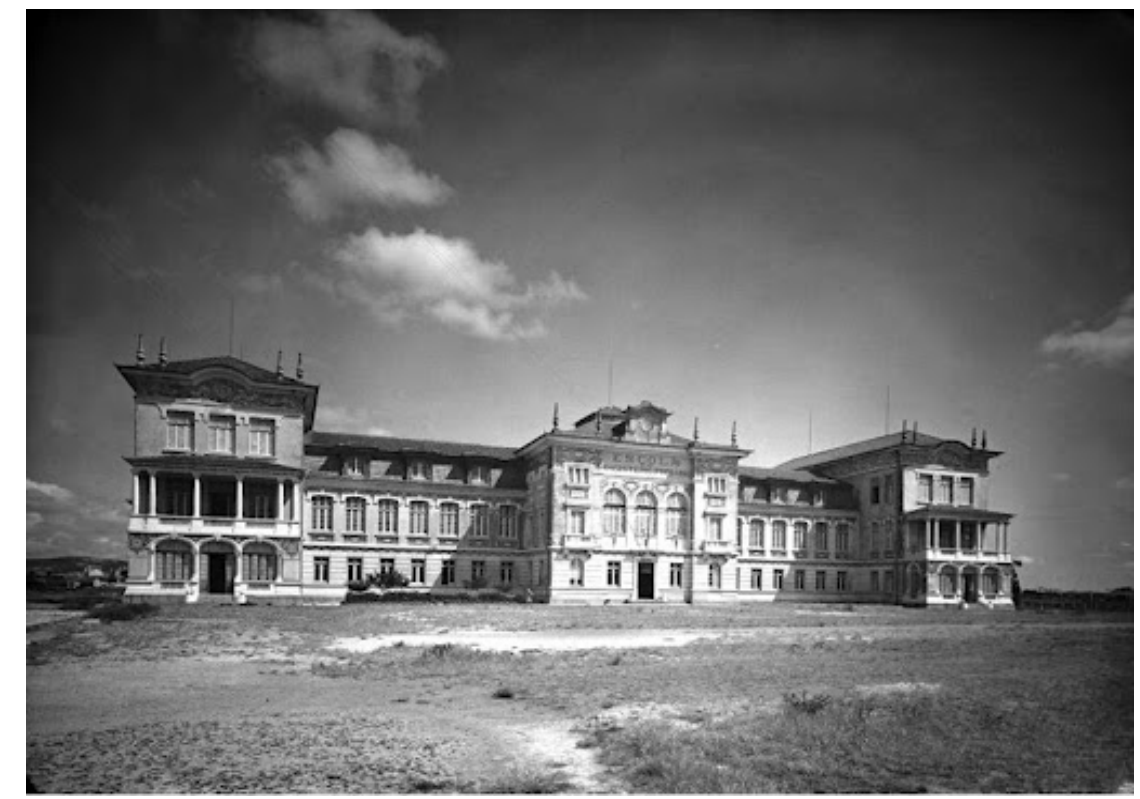

Escola do Magistério Primário de Lisboa: fachada principal. Estúdio Mário Novais. Biblioteca de Arte da Fundação Calouste Gulbenkian. [post. 1930]

\section{Pedagogia e Didática Geral e Didática Especial}

O decreto-lei n. ${ }^{\circ}$ 32243, de 5 de setembro de 1942 (PORTUGAL, 1942), cria duas disciplinas centrais à aprendizagem dos alunos mestres: a Pedagogia e Didática Geral e a 
Didática Especial. A primeira dedica-se ao estudo das normas e princípios que devem nortear as técnicas de ensino e aprendizagem. A Didática Especial analisa a especificidade de cada matéria e as dificuldades no ensino de cada disciplina. Nas palavras de Moreirinhas Pinheiro (1996b), "podemos classificar a Didática em: geral e especial. A primeira estuda os métodos, processos, formas e modos de ensino com caráter genérico, isto é, segundo as suas próprias leis. A Didática especial aplica-se a uma determinada matéria para a sua mais fácil e reta compreensão [...]." (p.63). Ambas passam a desempenhar um papel fulcral na preparação teórica dos alunos mestres das Escolas do Magistério Primário.

Analisando com mais pormenor o decreto-lei n. 32243 verifica-se que a disciplina de Pedagogia e Didática Geral apresentava uma carga horária semanal de 5 horas, sendo dada apenas no $1 .^{\circ}$ semestre. Por outro lado, a Didática Especial tinha uma carga horária semanal de 6 horas, sendo lecionada no $2 .^{\circ}$ e $3 .^{\circ}$ semestre.

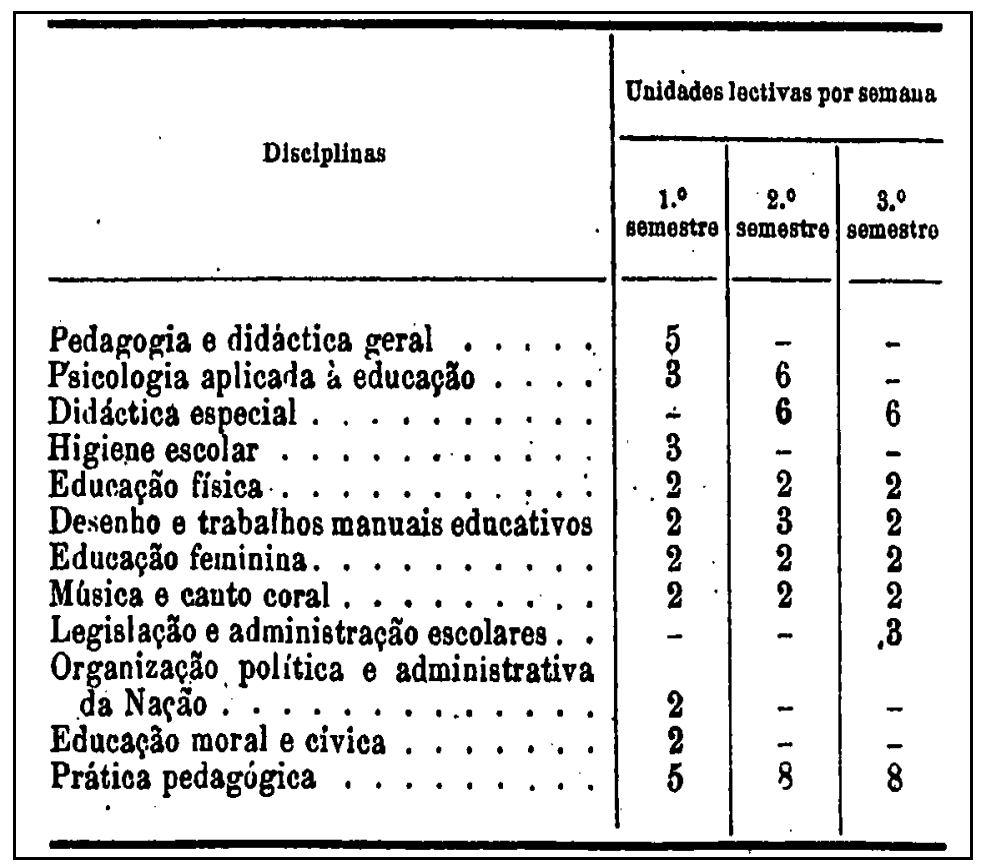

Decreto-lei 32243, de 5 de Setembro de 1942: plano de estudos

O ensino destas disciplinas tinha repercussões nas Práticas Pedagógicas, que eram, em grande medida, da responsabilidade dos professores de Didática Especial e abrangiam diversas atividades nas respetivas aulas. Assim, durante o primeiro semestre era dada primazia à "assistência aos trabalhos escolares nas escolas de aplicação", enquanto no segundo semestre esta assistência era complementada com a "realização de lições na aula de didática especial", sendo o terceiro semestre dedicado a estas duas atividades, acrescidas do facto de ser o período em que os alunos mestres começavam a lecionar turmas nas escolas de aplicação. O último semestre era destinado ao estágio "junto de um professor escolhido, numa escola em funcionamento." (decreto-lei n. ${ }^{\circ}$ 32243, preâmbulo, p.1140). 


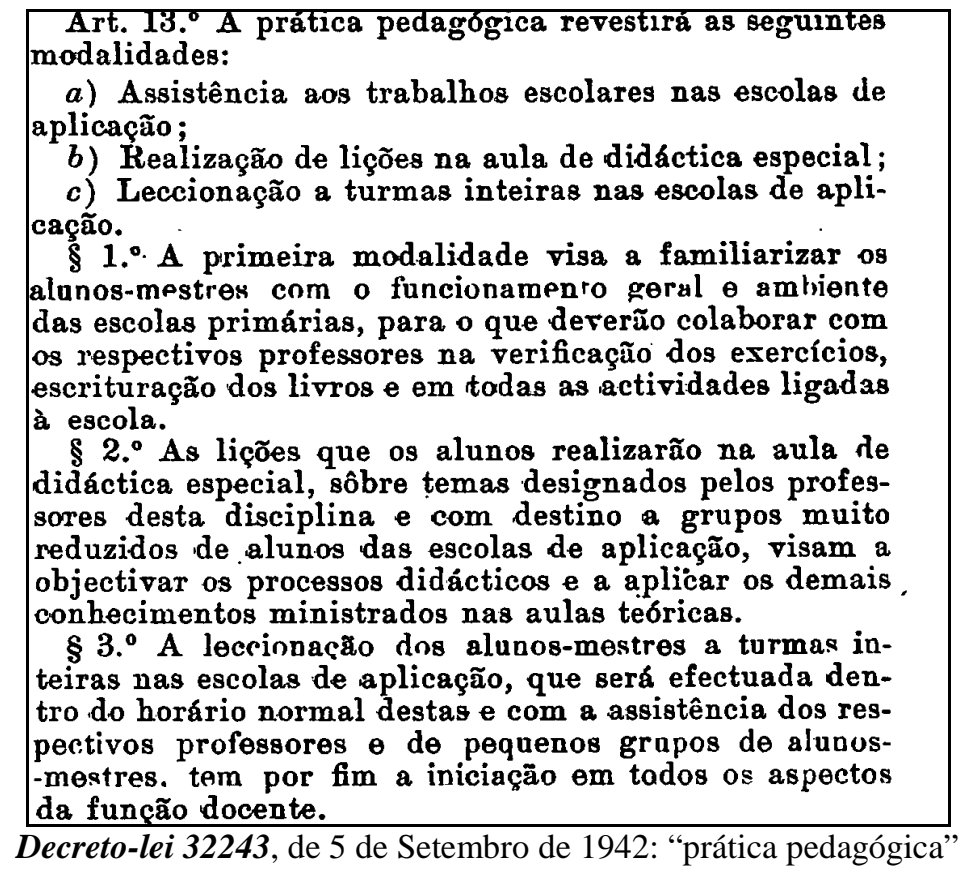

O decreto-lei n. ${ }^{\circ}$ 32629, de 6 de janeiro de 1943 (PORTUGAL, 1943), traz a público os programas das Escolas do Magistério Primário. A disciplina de Pedagogia e Didática Geral surge dividida em duas ordens de estudos, compreendendo a primeira considerações genéricas sobre o processo educativo, tentando elucidar os objetivos e a função social do ser professor, sendo que "não deverá ocupar os cuidados do professor por

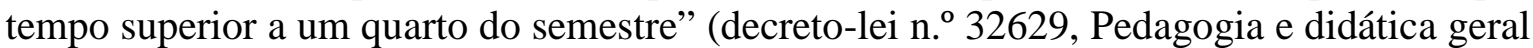
- Instruções, p.32). O programa inclui ainda matérias como a definição e aplicação do conceito de educação, especificidades e condicionalismos individuais, sociais e naturais do processo educacional, a disciplina e a instrução como meios para atingir o processo integral de desenvolvimento. A segunda ordem de estudos respeita à Didática Geral, considerada "teoria e prática de aprendizagem" (p.32), direcionada para a capacidade dos alunos estarem predispostos para a observação e sentido crítico, conseguindo desenvolver, de forma construtiva e evolutiva, a sua análise, sob a orientação do professor.

Por sua vez, à disciplina de Didática Especial era atribuído um caráter essencialmente prático, em que à "exposição magistral deve ser preferida a exemplificação. Para esse efeito, o professor terá sempre na aula dois alunos das escolas anexas, escolhidos entre as diferentes classes, consoante a matéria didática que tiver de se esclarecer [...]." (decreto-lei n. ${ }^{\circ}$ 32629, Didática Especial - Instruções, p.35-36) A Didática Especial dedicava-se a áreas específicas. Essas áreas eram a Didática da aritmética, da leitura, da escrita, da ortografia, geografia, história pátria, desenho e trabalhos manuais. Por último, a processologia didática também era considerada fundamental. Relacionada com a vertente mais prática do estudo, abordava questões como a distribuição dos alunos pelas classes, o horário escolar, as lições e a preparação das mesmas e também a atitude que um futuro professor deveria ter, em termos de linguagem e disciplina, complementada com as regras a que a organização, execução e julgamento de exames deveriam obedecer, não esquecendo a boa orientação nas atividades extracurriculares.

Os dois decretos citados mantiveram-se em vigor até 1960, ano em que é publicado o decreto-lei 43369, a 2 de dezembro (PORTUGAL, 1960), na sequência do qual se verificam alterações significativas na disciplina de Didática Especial. Esta mudança procurava responder à situação, aí identificada, das habilitações dos candidatos ao 
magistério primário serem insuficientes, por terem a "habilitação mínima do $2 .^{\circ}$ ciclo liceal ou equivalente, ou com o curso das secções preparatórias para os institutos industriais e comerciais e para as escolas de belas-artes". Por esta razão, tornou-se necessário, segundo esse diploma legal (Preâmbulo do Decreto-lei n. ${ }^{\circ} 43369$, p.2674):

Intensificar o estudo da didática especial, acrescentando aos seus anteriores objetivos a prévia revisão e o desenvolvimento das matérias relacionadas com os programas do ensino primário, com vista à sua integração didática subsequente, para o que se aumentam os respetivos tempos letivos e se cria, em cada escola do magistério, mais um lugar de professor dessa disciplina.

Desta forma, a disciplina desdobra-se em grupo A e grupo B, sendo lecionada por dois professores, durante quatro semestres, com uma carga horária semanal de três horas no primeiro semestre e de duas horas nos restantes, para cada grupo. $\mathrm{O}$ grupo A passa a abranger a Língua Portuguesa, História e Desenho; o grupo B inclui Aritmética e Geometria, Ciências Geográfico-naturais e Trabalhos Manuais. A duração do curso foi estabelecida em quatro semestres, ao invés dos anteriores três semestres letivos seguidos de um estágio, também semestral, o que resultou do facto de ser considerado "mais útil que a aprendizagem se revista, durante o estágio, de um carácter teórico-prático que permita a teorização da prática e, por outro lado, possibilite a aplicação das noções teóricas" (Idem, p. 2675).

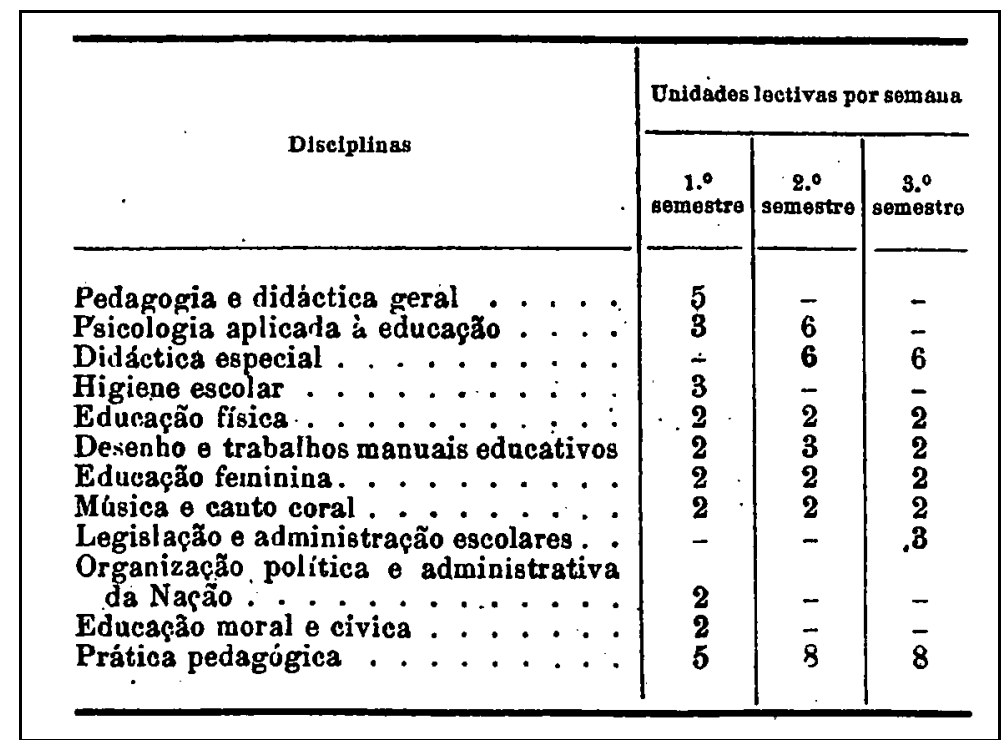

Decreto-lei 43369, de 2 de dezembro de 1960: plano de estudos

Além disso, os alunos deixaram de realizar o seu estágio noutras escolas, exteriores às escolas do magistério, e passaram a fazê-lo nas escolas de aplicação ou escolas anexas. Os professores de Didática Especial passam ainda a reger a disciplina de Legislação e Administração Escolares e poderiam ser nomeados definitivamente depois de dois anos de serviço considerado "bom e efetivo", através de concurso composto de provas escritas e orais. Em cada uma das escolas do magistério primário passou também a funcionar um conselho das escolas de aplicação, composto por todos os professores destas escolas e pelo professor de Didática especial, o qual realizava a coordenação entre estas escolas e as escolas do magistério, assistindo às práticas dos alunos. 


\section{Os professores}

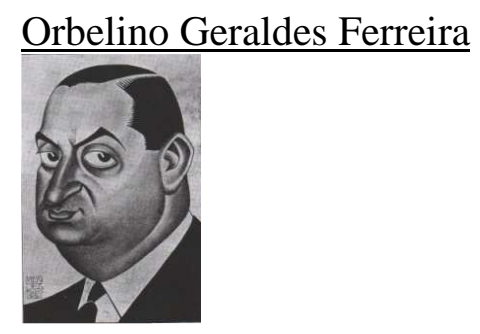

Nasceu em 18 de Julho de 1914 em Vila Nova de Foz Côa. Filho de professores dedicou-se ao ensino primário e à formação de professores. Licenciou-se pela Escola Normal Primária de Coimbra e exerceu atividade de professor nas Escolas de Santa Ovaia, em Oliveira do Hospital e em Vila Nova de Tazem até 1943, ano em que é nomeado professor de Didática Especial e de Legislação e Administração Escolares na Escola do Magistério Primário de Lisboa. Com a remodelação operada pelo Estado Novo, através do

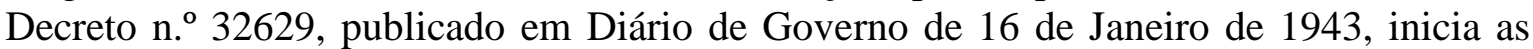
suas funções já com as alterações na disciplina que leciona, permanecendo no cargo até 1958, ano em que é transferido por motivos disciplinares para a Escola do Magistério Primário de Vila Real.

Entre a sua obra podemos encontrar as Notas de didática especial (em colaboração com José Maria Gaspar), de 1944, sendo o manual utilizado nas aulas desde o ano de 1948, Legislação e administração escolares (também em colaboração com José Maria Gaspar), de 1945, a Tradição pedagógica portuguesa, de 1952, ou a Didática prática, do ano de 1953. Publica também alguns artigos na revista Educação, entre 1949 e 1951, e no jornal $O$ educador, com uma página intitulada "Magistério primário", frequentemente sob o pseudónimo "Maria santarina". 


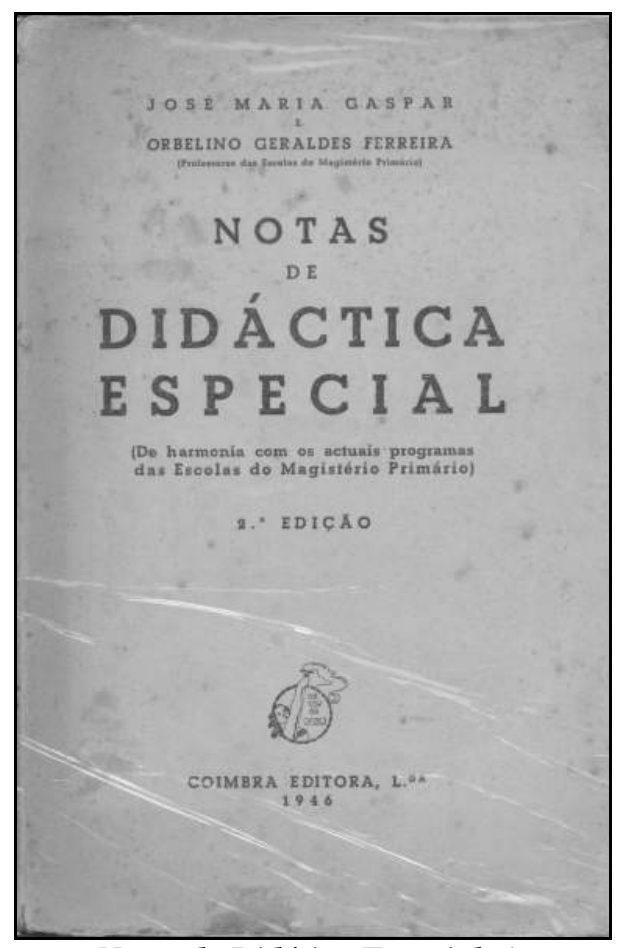

Notas de Didática Especial, de

Orbelino Geraldes Ferreira e José

Maria Gaspar, 3. ${ }^{a}$ ed.,1946

Os seus escritos debruçam-se sobre a metodologia e a didática, nas suas diversas áreas, como a aritmética, leitura, escrita, ortografia, geografia, história, desenho, trabalhos manuais ou moral cristã, observando-se este aspeto no seu "programa de didática prática (para professores e regentes de ensino primário elementar)", criado com base nas alterações introduzidas pelo Decreto de 1943, acima referido. Este programa, que está dividido em quinze capítulos, para além de ser dedicado a esta ciência da educação aplicada aquelas áreas, também apresenta uma preocupação com a organização pedagógica da escola e das salas de aula, com a profissão do professor, as principais qualidades que deve ter, a motivação que incute aos seus alunos na aprendizagem ou ainda um último capítulo dedicado a casos escolares, disciplinares e obrigações diárias, mensais e anuais dos professores. Viria a falecer em Lisboa em 13 de Janeiro de 1965 (NÓVOA, 2003).

\section{Octávio Neves Dordonnat}

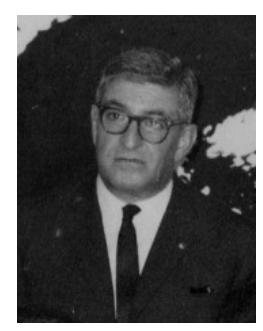

Nasceu em Lisboa em 4 de Julho de 1912 e licenciou-se em Germânicas pela Faculdade de Letras da Universidade de Lisboa. Exerceu funções como professor do ensino secundário, no liceu Jaime Moniz no Funchal e no Liceu Francês em Lisboa. Em 1943 começa a exercer funções na Escola do Magistério Primário de Lisboa como diretor, 
atividade que mantém até 1974, sendo simultaneamente professor das cadeiras de Pedagogia e Didática Geral e de Psicologia aplicada à Educação. Para apoio à disciplina de Pedagogia e Didática Geral é aprovado o manual publicado nesse mesmo ano de Francisco de Sousa Loureiro, professor e diretor da Escola do Magistério Primário de Coimbra, Lições de Pedagogia e Didática Geral.

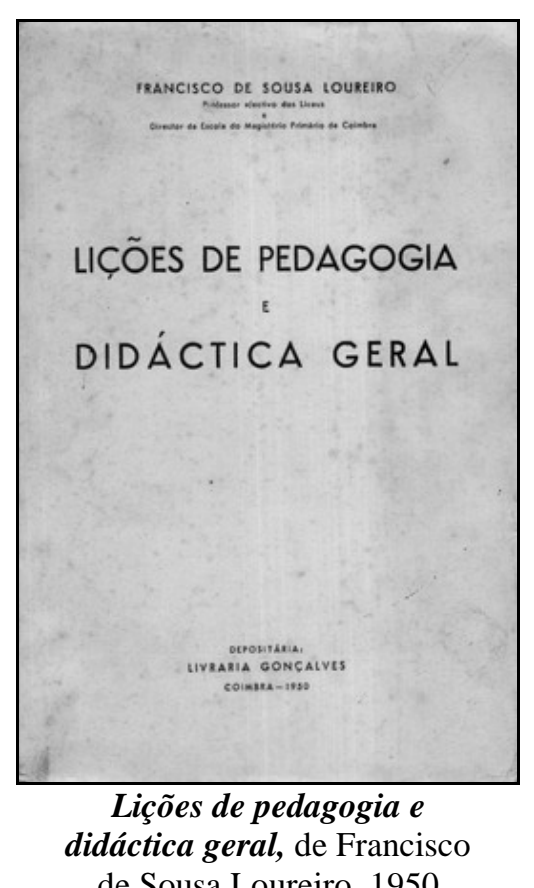

Durante a permanência na Escola, Dordonnat dirige as revistas Educação e Magistério, publicações que são criadas pelos professores e alunos, nas quais também redige artigos. Colabora na imprensa pedagógica com temáticas dedicadas à educação, à formação de professores ou cogitações sobre a criança e a aprendizagem. Além dos artigos que publica nas revistas da Escola do Magistério Primário de Lisboa, também se dedica a explorar os referidos assuntos no Boletim do Sindicato Nacional dos Professores, Educador, Encontro, Escola Portuguesa, Liceus de Portugal e Seiva. Em 1974 é obrigado a abandonar a escola, devido às alterações políticas decorrentes da Revolução do 25 de Abril, data em que regressou à docência no Liceu D. Pedro V até à sua aposentação. Viria a falecer em Lisboa em 15 de Maio de 1999 (NÓVOA, 2003). 


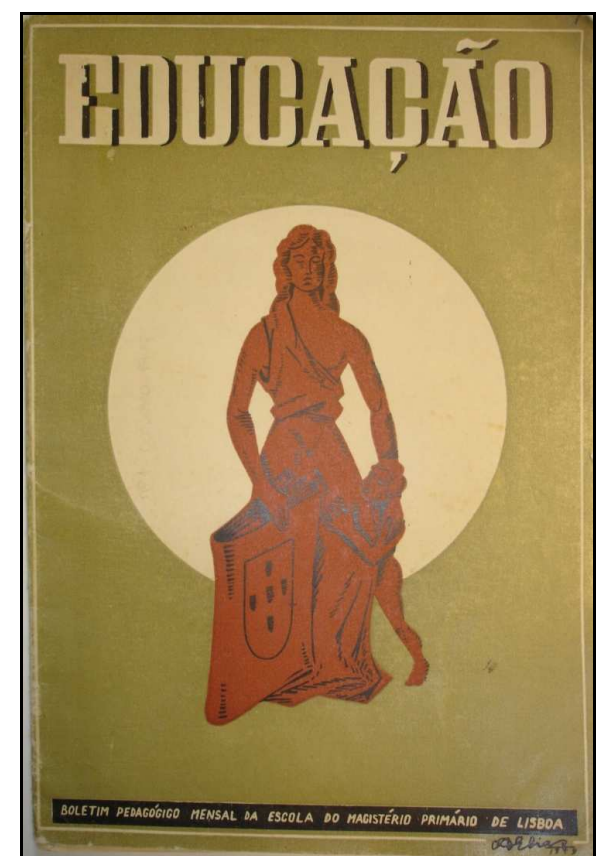

Revista Educação: Boletim pedagógico

Mensal da Escola do Magistério Primário de Lisboa

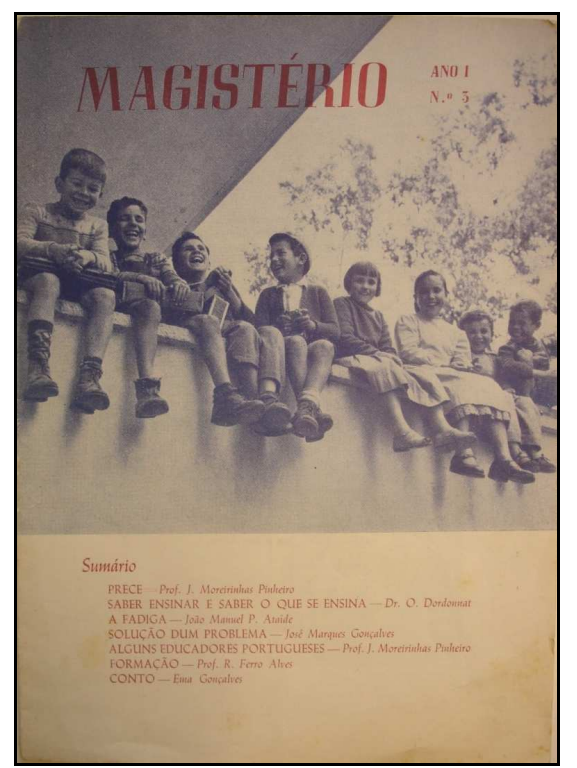

Revista Magistério, ano I, n. ${ }^{\circ} 3$

$\underline{\text { José Eduardo Moreirinhas Pinheiro }}$

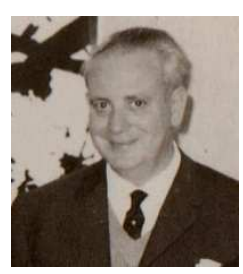

Nasce a 20 de Agosto de 1923 em Coimbra. Em 1944 conclui o Curso Complementar de Letras no Liceu Nacional de D. João III em Coimbra e em 1946 conclui, 
na Escola do Magistério Primário da mesma cidade, o Curso para o exercício do Magistério. Nesse ano, é nomeado professor agregado da Escola Masculina de Santa Cruz, em Coimbra, e no ano seguinte da Escola Masculina de Santo António do Olivais, na mesma localidade, passando a professor efetivo da Escola Masculina de Buarcos, Figueira da Foz, ainda nesse ano. Em 1954 torna-se professor efetivo da Escola Masculina da Figueira da Foz e, em 1958, é nomeado professor de Didática Especial e de Legislação e Administração Escolares da Escola do Magistério Primário de Lisboa, passando a professor efetivo em 1965. Quando iniciou funções relata que "senti-me um pouco aturdido devido ao número de alunos que me foram confiados e às 32 horas semanais que me foram atribuídas. Nessa época frequentavam a Escola cerca de 250 alunos do $10^{\circ}$ e $2 .^{\circ}$ anos...(...)" (PINHEIRO, 1996a, p. 10). Após o desdobramento da cadeira de didática especial nos grupos A e B, em 1960, ainda se dedica, até 1963, tanto à docência de uma como de outra, tendo, a partir desta data, a sua atividade restrita apenas ao ensino da Didática A, ou seja, o grupo que integra a Língua Portuguesa, História e Desenho. Para apoio às suas aulas utiliza o manual Introdução ao estudo da Didática Especial, da sua autoria. A 1. a edição está datada de 1960, tendo resultado da iniciativa de alunas e alunos, que compilaram apontamentos das suas aulas. A 2. ${ }^{a}$ edição, de 1961, já conheceu uma revisão mais profunda por parte do autor, que ampliou a obra. Finalmente, a $3^{a}$ edição, de 1967, é dedicada à Didática A, disciplina em que o autor se especializara. Em 1975 rege as cadeiras de Introdução à Pedagogia e de Didática Geral nos cursos especiais de Regentes e em 1976 é nomeado Diretor da mesma escola, ficando no cargo até ao ano de 1977. A partir deste ano letivo, leciona a cadeira de Metodologia. Em 1988 é integrado nos quadros da já então designada Escola Superior de Educação de Lisboa, na secção de reservados do Centro de Documentação e Informação, adstrito à Biblioteca. Aposentou-se em 20 de Agosto de 1993.

Entre a sua vasta obra podemos destacar No centenário de Ovídio Decroly, de 1971, A lição de geografia no método Decroly, 1973, Notas sobre a Escola Normal Primária de Lisboa e alguns dos seus mestres, 1976, Vem brincar comigo!..., de 1979, Do ensino normal na cidade de Lisboa 1860-1960, de 1990, Escritos vários relativos á Escola Normal Primária e à Escola do Magistério Primário de Lisboa, de 1996, Inventário de livros raros e desconhecidos: memória da Escola Portuguesa (do séc. XVIII ao séc. XX), de 2009, entre outras obras. Publicou também artigos em diversas revistas ligadas à temática da educação, tais como Escola Portuguesa, Ocidente, Magistério, Escola Democrática ou a Revista Municipal de Lisboa.

Continua a dedicar algum do seu tempo aos reservados da Escola Superior de Educação de Lisboa e a auxiliar investigadores nacionais e internacionais. 


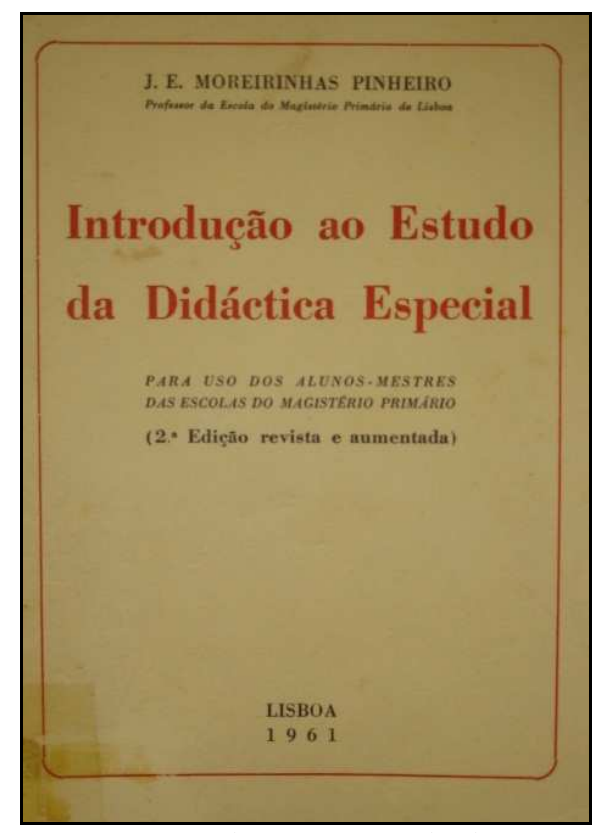

Introdução ao estudo da

Didáctica Especial, de J. E.

Moreirinhas Pinheiro, 2. ${ }^{\mathrm{a}}$ ed., 1961

\section{Ideologia, religião e moral nos manuais de pedagogia e didática}

Um dos traços mais marcantes da obra de Francisco de Sousa Loureiro (1950), o autor utilizado por Octávio Dordonnat nas suas aulas, é a sua adesão clara aos valores do regime salazarista. Segundo ele, a formação dos alunos deve ser orientada "por princípios ou valores ideológicos como Deus, Pátria e Família" (p.12), numa referência explícita à celebrada trilogia da "educação nacional" presente num dos quadros de "a lição de Salazar". Ao falar da Mocidade Portuguesa e do seu contributo para o fomento da educação física e do espírito de sacrifício entre os jovens, Loureiro considera ser "digna do maior louvor a ação desenvolvida pelo Estado Novo nesta matéria" (p.13). Fazendo apelo à identidade nacional, defende que todos os portugueses, "daquém, ou dalém mar", "deverão sair da «sagrada oficina das almas» sempre e só portugueses duma só fé" (p.42), numa alusão à conhecida analogia expressa por Salazar. Noutro momento, referindo-se ao próprio ditador, aponta "o exemplo de Salazar [como sendo] dos que mais profundamente pode ilustrar a Pedagogia" (p.45). Finalmente, lembrando outra das grandes referências do regime, proclama que "o Estado tem o direito de, através da Escola, criar no aluno o sentimento da unidade imperial" (p.149). Não obstante estarmos perante um compêndio de pedagogia e didática geral, e da retórica técnico-científica que o caracteriza, o discurso político-ideológico é uma constante, o que resulta, provavelmente, da consciência de que ele se destina à formação dos futuros educadores do povo. Procura-se, assim, assegurar, à partida, a sua adesão aos valores do regime, até porque o professor surge apresentado como "um exemplo, um modelo vivo da mais pura moralidade" (p.16), lugar-comum habitual em discursos de sentidos diferentes sobre a profissão.

A dimensão ideológica está, igualmente, muito presente no manual de José Maria Gaspar e Orbelino Geraldes Ferreira (1944), utilizado por este último na escola de Lisboa. Pegando no exemplo do ensino da geografia e da história, cuja articulação é defendida, um elemento central, em ambas as disciplinas, é a assunção da finalidade nacionalista e 
imperial do respetivo ensino. Fórmulas usadas na propaganda salazarista, como "Portugal não é um país pequeno" (p.297), encontram-se espalhadas pelo manual. As referências à Pátria e ao Império são uma constante: "[O ensino da Geografia] pretende, antes de mais, que saibam ver neles [mapas] a grandeza lisonjeira dum Império que é nosso há 500 anos" (p.302); "Formar portugueses, bons patriotas, eis o objetivo do ensino da História de Portugal" (p.355). É clara a defesa de centralidade da "educação espiritual" (p.390). É, mesmo, assumido um certo alinhamento político, ao defender-se a "escola nacionalista" contra o "internacionalismo pedagógico" (p.345).

Nessa ótica, o professor deve ser funcional em relação ao Estado, deve servi-lo sem reservas. Os exemplos são muitos. Em relação ao cumprimento estrito dos programas, Gaspar e Ferreira sentenciam: "Não discutimos o programa: cumprimo-lo" (p.288). Ao professor, funcionário (e servo) do Estado, recomenda-se, a este respeito, prudência, disciplina e respeito pela hierarquia: "De passagem se frisa, contudo, que não deve ser o professor oficial a discordar. Uma boa disciplina de funcionário impõe-lhe o dever de servir o Estado (que lhe paga) como ele quer ser servido" (p.349). Para além da eficiência didática, impõe-se uma adesão clara ao regime: "Para isso necessita o professor tanto de saber Didática como de ter convicções" (p.302).

Esses valores surgem em estreita articulação com os do catolicismo, como fica claro na afirmação de Francisco Loureiro (1950) de que a "a doutrina cristã, concebendo o homem numa dualidade de corpo e alma, é o mais sólido e completo sistema de moral - a verdadeira escola de virtudes, o esteio mais forte e amoroso que foi dado aos povos" (p.18). O último elemento da trilogia, a família, merece igualmente destaque, por ser, acima da escola, a "primeira educadora". A resposta a uma questão muito discutida na época -a quem cabe educar: Igreja, a Família ou a Escola?-, assume como referência a Encíclica da Educação Cristã da Juventude devida a Pio XI.

Comparativamente com os manuais das décadas anteriores, o compêndio de Moreirinhas Pinheiro (1961) é bem menos ideológico, o que decorre não só do contexto, já um pouco diferente, em que é produzido mas, em especial, da própria posição pessoal do autor sobre esta matéria. Em várias ocasiões, nos seus textos de memórias, somos confrontados com apontamentos críticos em relação à situação vigente, sendo lembrado mesmo o seu apelo ao voto em Humberto Delgado. Mesmo assim, não deixam de estar presentes na Introdução ao estudo da Didática Especial algumas das grandes referências doutrinárias de então, como quando, referindo-se às finalidades da História, o autor considera que esta deve contribuir para despertar "uma consciência cívica e o amor à Nação", sendo guiada pelos "princípios de Deus, da Pátria e da Família" (p.90). No entanto, as referências são, principalmente, de origem religiosa, não escondendo o autor as suas convicções, como se pode ver na passagem seguinte: "Deve também o professor ensinar a criança a ler o livro maravilhoso da natureza e fazer-lhe compreender que o autor sublime de tanta coisa bela foi Deus, autor de todas as coisas visíveis e invisíveis, omnipotente e omnisciente, bom e justo" (p.103-104).

Em linha com uma tradição mais que secular, a finalidade atribuída à educação no conjunto dos manuais em análise é o integral desenvolvimento da pessoa humana, na diversidade das suas dimensões: física, intelectual, moral e religiosa. Ou seja, a pedagogia salazarista apropria-se de um ideal, o da formação integral dos jovens, igualmente assumido pelas correntes renovadoras do início do século, ainda que interpretado agora num quadro conservador e religioso. As preocupações, por exemplo, com a educação física e a educação moral mantêm-se, mas com objetivos e conteúdos parcialmente distintos.

No caso de Moreirinhas Pinheiro, para além da dimensão religiosa já aqui identificada, as suas conceções vão ao encontro daquilo que podemos considerar como uma espécie de 
humanismo, por exemplo quando se propõe "formar homens dignos desse nome, bons e belos". Essa perspetiva de formação integral está presente, por exemplo, no ensino da aritmética que apresenta como finalidades, na ótica do autor, desenvolver as "faculdades da memória, do juízo e do raciocínio", a par do "sentimento moral" e dos "bons hábitos" (p.57). A propósito destes últimos, o autor adianta:

A aquisição de bons hábitos é muito importante no ensino da Aritmética, pois estes dão à criança certa disciplina mental indispensável à marcha das atividades escolares. Neste ponto deve o professor desenvolver nos seus alunos hábitos de trabalho, perseverança, ordem, limpeza, cautela, simplicidade, exatidão, clareza, etc. (p.57)

Ou seja, para além dos conhecimentos e competências por ela proporcionadas, a aritmética, uma disciplina aparentemente neutra, é aqui encarada como uma área decisiva para a formação do carácter dos educandos, no que se refere a determinadas atitudes, consideradas decisivas do ponto de vista da regulação social, em particular as que têm por base os valores do trabalho, da ordem ou da limpeza, consideradas essenciais para a construção do escolar no sentido moderno e, em particular, no que diz respeito ao governo de si mesmo.

\section{Pedagogia e Didática: "ciência" e "arte"}

$\mathrm{Na}$ sequência de outra longa tradição, presente na generalidade dos manuais desde o final do século XIX, a pedagogia surge definida, no início da obra de Francisco Loureiro (1950), como sendo "a ciência e a arte da Educação" (p.11), formulação que remete, por um lado, para o carácter científico dos seus princípios e, por outro, para a dimensão eminentemente prática que reveste a sua aplicação ao trabalho docente, considerado como "arte". No mesmo sentido, a didática é apresentada como "a ciência e a arte da aprendizagem" (p.81), o que remete, simultaneamente, para as suas componentes teórica e prática, para além de sublinhar o lado da aprendizagem, valorizado pelas correntes renovadoras.

No que se refere à Didática, Moreirinhas Pinheiro (1961) define-a de forma idêntica, ou seja, simultaneamente, como "ciência e arte". Ciência por ser "um conjunto sistemático de conhecimentos com objeto próprio, método e leis". Arte por ser "uma aplicação de conhecimentos à realização de uma conceção" (p.10-11). O movimento tendo em vista a afirmação da pedagogia como ciência da educação, em decurso desde o final do século XIX e que continuava a marcar a pedagogia presente nas escolas de formação de professores ao longo do período salazarista, não punha de parte o entendimento da mesma como uma "arte", em particular no que se refere à sua concretização prática. Isso está claramente presente, por exemplo, na conceção de professor que o compêndio propõe:

O mestre deve possuir vasta preparação científica e encontrar-se na posse das técnicas indispensáveis ao bom exercício da sua missão. Deve adaptar essas técnicas à sua maneira de ver e de sentir. Tem o educador, neste ponto, de ser também humanista, pois nada do que é humano lhe pode ser ignorado. Para tal, urge conhecer as faculdades físicas, morais e intelectuais do educando e moldá-las com mãos de artista consciente, com inteligência e amor. O mestre será também poeta, pelo seu estado de alma, determinado por vibração subjetiva de professor artista. (p.10) 
A anterior citação é particularmente interessante por várias razões. O professor é aqui visto como "mestre" ou "educador", o que realça a dimensão humana da relação com os discípulos e a influência que, a esse nível, deveria exercer sobre eles. O recurso à metáfora do "molde" é, a esse propósito, significativo como também o é a referência ao "humanismo" do mestre. O cunho afetivo dessa relação é sublinhado quando o autor se refere ao "amor" que deveria estar presente no ato de modelação, acompanhando a "inteligência" do mestre. Para além de artesão, oficial da sua "arte" de aplicação, o professor é aqui encarado como "poeta" ou "artista", o que nos remete para a dimensão estética do ato de ensinar, tal como é visualizado pelo autor. Em diálogo com as raízes religiosas da profissão, o trabalho do professor é visto como uma "missão", o que não põe em causa a necessidade de uma "vasta preparação científica" e a "posse das técnicas indispensáveis" a um bom exercício. Esta definição compósita, articulando categorias tradicionais e modernas, tornou-se, na verdade, recorrente nas representações difundidas sobre a profissão até aos anos 60 do século $\mathrm{XX}$, designadamente por via dos manuais de pedagogia e de didática que procuravam apresentar aos alunos-mestres modelos idealizados (e considerados legítimos) de se ser professor.

A articulação entre as componentes de "ciência" e de "arte", tanto no caso da pedagogia como no da didática, conduz a generalidade dos autores, eles próprios formadores de professores, à valorização sem reservas da formação. É o caso da obra de Gaspar e Ferreira (1944) em cujo início se proclama: “um bom professor se não improvisa [...] o cuidado na preparação de mestres precisa de ser tão pormenorizado nos primários como nos superiores" (p.5).

\section{Genealogia da modernidade pedagógica: "escola antiga" versus "escola moderna"}

Não obstante as abundantes referências ideológicas de conotação conservadora e católica, os autores da Escola Nova são abundantemente referenciados no manual de Francisco Loureiro, por vezes para os criticar, mas, também, muitas vezes para aceitar as suas propostas. Montessori, Decroly, Claparède, Ferrière, Dewey, Kilpatrick, Thorndike, Freinet e Aguayo estão entre as fontes com que o autor vai dialogando ao longo do texto, em alguns casos com frequência. Outros autores da tradição renovadora estão, igualmente, presentes como Comenius, Rousseau, Herbart e Compayré. Para o caso português, surgem referenciados Émile Planchard, este bastas vezes, e Mário Gonçalves Viana, entre outros. A presença recorrente dos educadores da Escola Nova é articulada e contrabalançada com o recurso a autores da corrente conservadora, em particular o italiano Lombardo Radice.

Parte substancial da componente de didática do manual é, em correspondência com o definido no programa, dedicado aos chamados métodos de aprendizagem. A maioria dos métodos indicados resulta do contributo da Escola Nova, com destaque para o "Método dos projetos ou de Dewey", o "Método dos complexos ou centros de interesse" (Decroly), o "Método do jogo" ou o "Método dos problemas". Muito valorizado, e considerado a base de tudo, é o "Método dos passos formais" de Herbart, autor de referência no que diz respeito à construção da pedagogia como ciência, designadamente na sua expressão didática. Na opinião de Loureiro (1950), "a sua doutrina, nas suas linhas gerais, tem uma atualidade impressionante" (p.99).

As referências aos autores da Educação Nova são maioritariamente positivas, não obstante algumas críticas. Dewey, por exemplo, é considerado "o pai da educação renovada" e "o filósofo da educação da corrente sociológica". Algumas das suas teses mais popularizadas, como a ideia de que a educação da criança se deve fazer "para a vida e pela vida" e a de que a escola deve ser "uma sociedade em miniatura" (p.103-104) são 
apresentadas sem aparente distanciamento. $\mathrm{O}$ método dos projetos, relativamente ao qual o próprio autor elabora exemplos, só merece a ressalva de que não pode ser exclusivo nas escolas europeias, por requerer muito tempo e a não sujeição a programas e materiais. Sobre Decroly, cujo método é apresentado com detalhe, Francisco Loureiro (1950) conclui:

\begin{abstract}
Os seus centros de interesse são magníficos no ponto de vista técnico [...] Por experiência própria, poderíamos demonstrar que a técnica de Decroly, aplicada em disciplinas com um programa definido, dá magníficos resultados em economia de tempo, facilidade de aprendizagem e segurança de conhecimentos, porque é possível associar muitos conhecimentos a um fundamental, central ou essencial, formandose com ele um centro de estudo. (p.108-109)
\end{abstract}

Por fim, o autor diz preferir a expressão "centro de estudo" à de "centro de interesse" para se demarcar do que considera ser "o hedonismo naturalista de Decroly à base de necessidades materiais" (p.109). Este é, de resto, um bom exemplo em relação à atitude habitual, perfilhada por Loureiro, de apropriação crítica da herança renovadora, mais concretamente, e parafraseando Eugène Dévaud, de conjugação do "sistema Decroly" com a "pedagogia cristã" (p.109).

O autor manifesta, ainda, um grande apreço pelo "método de problemas", sendo a sua descrição dos passos envolvidos baseada na obra Didática da Escola Nova do educador latino-americano A. M. Aguayo. Num balanço final, afirma o seguinte: "A atividade da escola na resolução de problemas é importantíssima, porque dá ao aluno maior capacidade mental, adestrando-o para a resolução de muitos que a vida lhe apresenta" (p.118). É idêntico o apreço que mostra pelos "jogos educativos", cuja fundamentação vai buscar a Claparède, Decroly e Maria Montessori e que relaciona com o "conhecimento psicológico da criança" e a valorização da atividade lúdica para que ela propende (p.114).

A referência a uma abordagem aparentemente bem mais tradicional, a assente no chamado "método acroamático", acaba por confirmar a nossa perceção de que as teses renovadoras têm uma presença nítida, ainda que combinada, no discurso dominante nas Escolas do Magistério Primário. Segundo Loureiro (1950), este método, baseado na exposição oral do mestre e que resulta da conjugação dos procedimentos "mnemónicos" e "dogmáticos" (embora possa beneficiar de novas técnicas, resultantes do uso do fonógrafo ou do rádio), não pode ser aplicado, de forma exclusiva, no ensino primário, "por não poder sustentar-se, durante muito tempo, a atenção das crianças" (p.122).

Por se tratar de um manual de didática especial, as propostas metodológicas presentes na obra de Gaspar e Ferreira (1944) surgem articuladas com as diversas disciplinas aí presentes. Por exemplo, no que se refere ao ensino da aritmética, os autores consideram dever este ser racional, concreto, prático e intuitivo e, mais precisamente, "partir do concreto para o abstrato, do conhecido para o desconhecido, do particular para o geral" (p.22). Surge assim clara a assunção dos referidos lugares-comuns da pedagogia moderna e propagandeados, entre outros, por Herbart e Spencer. No entanto, como já tínhamos encontrado em Francisco Loureiro, procuram situar-se numa pedagogia do meio-termo, do "justo equilíbrio": "Reagindo igualmente contra o muito velho e o muito novo, o professor moderno mede as possibilidades do programa e as exigências do horário de cada disciplina com os ditames de uma equilibrada arte didática" (p.23). Nessa conformidade, adiantam, "nem todos os processos usados hoje lá fora e apregoados cá por dentro podem pôr-se em 
prática entre nós". Todavia, admitem, "podem e devem modificar-se muitos dos velhos processos" e serem implementados "processos ativos que os velhos detestam" (p.21-22).

No que se refere aos métodos propostos para o ensino desta disciplina (a aritmética) e educadores que estão na sua base, voltamos a encontrar alguns dos mais enfatizados por Francisco Loureiro e oriundos da Escola Nova como os propostos por Montessori, Decroly, Cousinet ou o método Winnetka, desenvolvido nos Estados Unidos. A atitude dos autores é de grande abertura e ecletismo: "todos os métodos apresentados são utilizáveis no ensino das operações fundamentais" (p.47). Isso expressa-se, por exemplo, na valorização da tabuada e do recurso à memória na sua aprendizagem, a par da crítica ao abuso da "forma expositiva" e à pouca importância atribuída ao "cálculo mental" (p.49). O uso da "forma interrogativa" é, a esse propósito, explicitamente recomendado (p.41).

No que se refere ao ensino da Geografia ficam também claras a crítica de opções mais tradicionais ou a defesa de inovações pedagógicas. Os autores consideram, por exemplo, não ser esta uma "disciplina de ensinar sentado" (p.309), mas antes o contexto para uma aprendizagem intuitiva, racional, prática, gráfica e utilitária, desejavelmente ao ar livre. É criticado o uso do livro, bem como a memorização de nomenclaturas, e recomendado o recurso privilegiado a mapas e a "viagens reais e imaginárias" (p.325). Idêntica abordagem é indicada para o ensino da História. O maior defeito atribuído à "escola antiga", na terminologia dos próprios autores, "é o da memorização de datas e minúcias cronológicas, fatigando a criança com o inútil e asfixiando o ensino" (p.382), o que não põe em causa a necessidade de desenvolver o "sentido cronológico" nas crianças (p.386). Por isso se defendem as "boas conquistas da boa pedagogia" (p.357). Nela são incluídos os estudos de Decroly, Claparède e Bovet, entre outros, ainda que os autores se demarquem daquilo a que chamam uma "pedagogia socialista", identificando-a com Dewey, Ferrière, Kerschensteiner e respetivos seguidores.

Em Moreirinhas Pinheiro (1961) abundam os autores referenciados ao longo das páginas do compêndio, permitindo, na maior parte dos casos, traçar uma espécie de genealogia do pensamento educativo moderno. Se Rousseau prima pela ausência, alguns dos seus seguidores oitocentistas não deixam de marcar presença, como no seguinte excerto respeitante ao ensino das ciências:

Foi principalmente a partir de Pestalozzi e Froebel que os pedagogos se preocuparam com a sistematização dos métodos pedagógicos. Mas o educador que mais lucidamente ajustou as técnicas educativas às leis da psicologia foi, sem dúvida, Herbart.

Se nas várias disciplinas da escola primária, os passos formais de Herbart têm aplicação imediata, parece-nos que a nenhuma matéria eles se ajustam melhor do que ao ensino das ciências. (p.99-100)

Em seguida, são sistematizados os referidos passos: preparação, apresentação, associação, recapitulação e aplicação. Herbart surge, na verdade, como um dos autores de eleição de Moreirinhas Pinheiro. A formalização didática operada pelo educador alemão conhece, na verdade, uma ampla difusão tendo, em particular, grandes implicações no que diz respeito à formação de professores e aos manuais a ela associados, em particular pela regulação e coerência que procurava dar ao trabalho docente e à organização da aula.

Os autores do período entre o final do século XIX e as primeiras décadas do século XX, genericamente identificados com a chamada Escola Nova, estão entre os mais profusamente citados por Moreirinhas Pinheiro, com destaque para Decroly, Claparède e Montessori, ainda que também Dewey, Ferrière, Kilpatrick, Thorndike, Parkhurst, Dottrens 
e Piaget, entre outros, estejam incluídos nessa galeria. Acima de todos está Ovide Decroly, inquestionavelmente a grande referência teórica do autor:

O ensino da língua materna, pelo método Decroly, contribui para formar a personalidade da criança, pela expressão oral e gráfica das ideias bem compreendidas e normalmente assimiladas. Baseado na evolução da criança, respeita a espontaneidade da sua linguagem e aplica a função globalizadora à aquisição da leitura, da escrita e da ortografia. Esta espontaneidade deve ser estimulada pela conversação, pelas lições de coisas e por trabalhos individuais (geralmente integrados em centros de interesse) e desenvolvida por íntima relação entre exercícios de observação e de associação [...]

O método dos centros de interesse, baseado na psicologia da criança, torna-se ainda mais eficiente pela combinação com o método ativo: a criança, em lugar de receber passivamente um conjunto de noções prévias, participa ela mesma na sua elaboração, contribui para a procura de documentos e participa na feitura do material, na experimentação e na descoberta. Nada de mestre que fale enquanto o aluno escuta, mas sim, uma estreita colaboração, na qual a criança aprenda a aprender, a agir, quer dizer: a trabalhar. (p. 27 e 59)

O autor procura aplicar o chamado "método Decroly" às diversas áreas do currículo do ensino primário e noções como "função globalizadora" ou "centros de interesse" pontuam com frequência o texto. A opção de Moreirinhas Pinheiro pelo denominado "método ativo" é, de resto, bem clara. A par do de Decroly, outros "métodos" vão sendo propostos, quase todos eles dentro dessa tradição, como o "método Montessori" (p.60), "os modernos métodos de ensino individualizado: o plano Dalton, o método Winnetka e o método Mackinder" (p.86) ou o "método de projetos" (p.105-106). Em relação a este último, o autor apresenta as que considera serem as características de um bom projeto recorrendo, para tal, à sistematização de A. M. Aguayo. O educador latino-americano e divulgador da "escola ativa" é, sublinhe-se, outra presença incontornável ao nível da intertextualidade subjacente à escrita de Moreirinhas Pinheiro. Fontes incontornáveis da Introdução ao estudo da Didática Especial são ainda as obras de autores como o espanhol Solana, o italiano Lombardo Radice ou o brasileiro Theobaldo Miranda dos Santos. Este último, além de amplamente referenciado, vê três de entre as suas obras elencadas na bibliografia, sendo ainda adaptada dele a interessante "ficha de crítica e de orientação didática" destinada à "prática de ensino" e constante do final da obra. Os seus diversos compêndios para a formação de professores, publicados pela Companhia Editora Nacional, foram sucessos editoriais e circularam pelo mundo pedagógico contribuindo para a delimitação de uma pedagogia católica herdeira da Escola Nova na qual se inclui a produção de Moreirinhas Pinheiro e de muitos outros autores ligados à formação de professores durante o Estado Novo, muito em particular os professores de pedagogia e didática das escolas do magistério primário. Para a construção desse campo, o contributo das edições ou das traduções brasileiras é, sem dúvida, relevante, sendo Theobaldo Miranda dos Santos o mais influente desses autores, o que é atestado pela sua presença constante nas bibliotecas das referidas escolas (TOLEDO \& MOGARRO, 2011).

Embora isso seja visível nos três autores aqui referenciados, é em Moreirinhas Pinheiro que é mais sensível a dicotomia "escola antiga" - "escola moderna", transformada em lugar-comum dos discursos pedagógicos renovadores desde as décadas finais do século XIX. Referindo-se aos métodos de ensino da História, afirma o autor: 
$\mathrm{Na}$ escola antiga os factos eram apresentados de uma maneira rígida, expositiva, em que o compêndio desempenhava o principal papel. A escola moderna ou ativa utiliza também a exposição, mas exige mais do aluno. Deve dar vida à História, apresentar intuitivamente figuras e acontecimentos, criar cenas, excitar a fantasia e mobilizar a autoatividade dos alunos. (p.92)

De resto, o autor afirma-se, por mais de uma vez, partidário dos "modernos métodos", defendendo, em relação às diversas áreas do currículo, uma educação "ativa", "intuitiva", "prática" e "experimental". A defesa dos procedimentos intuitivos foi, em permanência, um dos traços definitórios das correntes renovadoras. Nesse sentido, a "observação" é considerada base da aprendizagem em algumas das áreas, em particular nas ciências naturais. Apela-se, ainda, ao "esforço de descobrir" por parte da criança (p.95). Referindose àquela mesma área, o autor afirma: "A forma socrática é a melhor no ensino desta matéria" (p.99). O diálogo socrático é, de resto, uma das estratégias mais valorizadas, na tentativa de implementação de métodos ativos, ao longo da primeira metade do século XX. A partir do exemplo da aritmética, o autor constata: "As correntes modernas deste ensino tendem para a utilização de processos globalizadores, orientados para os interesses e para a atividade lúdica da criança" (p.55). O tema do interesse da criança é, com alguma naturalidade, outra das marcas distintivas da chamada modernidade pedagógica, cujas categorias, como vemos, continuam presentes. Algumas opções habitualmente associadas à "escola antiga" merecem-lhe, igualmente, observações críticas como, por exemplo, os exames, que apresentariam "sérios inconvenientes" (p.85) ou a "enumeração de datas e batalhas sem qualquer significado" no que respeita ao ensino da História (p.90).

\section{Uma pedagogia do "meio-termo": por uma "escola ativa" mas com base na "tradição"}

Ao procurar sistematizar as opções pedagógicas a serem prescritas aos futuros professores, Francisco Loureiro (1950) tem as seguintes significativas afirmações:

Ao apresentar os métodos especiais, abstenho-me intencionalmente de preconizar a aplicação exclusiva de qualquer deles. Concedo mesmo que, com algumas adaptações e correções impostas pelo condicionalismo português, todos são suscetíveis de utilização, pelo menos para variar o ensino [...] Alguns são mesmo mais processos do que métodos e, nos que o são verdadeiramente, deve expurgar-se-lhe toda a base materialista e libertária, por ser incompatível com as tradições espirituais educativas da Nação portuguesa. (p.126-127)

Noutro momento, referindo-se ao papel do mestre e à auto-educação, o autor afiança que "os extremos são sempre perigosos" (p.165). Para além da exemplaridade, a que já nos referimos, o mestre deve destacar-se, segundo o autor, pela sua "personalidade", a qual deve ser expressão das "melhores virtudes do homem: carácter e amor". Só assim poderá aspirar a penetrar "na alma dos seus alunos" e imprimir neles "a beleza da educação" (p.170-171).

Parece ficar claro que a pedagogia difundida nas Escolas do Magistério Primário no período salazarista procura operar uma espécie de "casamento de conveniência" entre a herança da Escola Nova, extirpada das suas teses mais radicais e da sua habitual inserção 
ideológica e social, conjugada com alguns dos pressupostos de uma pedagogia católica e adaptada aos novos tempos conservadores e, mesmo, autoritários. Neste contexto, a expressão "escola ativa" vai parecer mais adequada para o enraizamento desta corrente no movimento renovador da educação que percorre a transição do século XIX para o século $\mathrm{XX}$ e as primeiras décadas deste último século.

A admissão da possibilidade de conciliar duas opções aparentemente antagónicas está muito presente, igualmente, no compêndio de José Maria Gaspar e Orbelino Geraldes Ferreira (1944), neste caso a conjugação entre uma "escola ativa" e uma "escola cristã" e "nacionalista", noutras palavras, entre o "progresso" e a "tradição".

Somos, como pode inferir-se deste trabalho, por uma escola ativa, tradicionalista, cristã e constantemente progressiva. Somos por uma escola portuguesa [...] A escola ativa não pode ser sinónimo de escola laica [...] Somos por uma escola com base na tradição porque só assim poderemos conseguir obra pedagógica experimentalmente nacionalista e cristã. (p.389-391).

A anterior citação representa uma excelente síntese das perspetivas pedagógicas prevalecentes durante boa parte do período salazarista e que têm uma expressão clara no conteúdo da pedagogia e das didáticas tal como são ensinadas nos contextos de formação de professores que são as Escolas do Magistério Primário, ideia esta já presente noutros estudos (MOGARRO, 2001, 2006). Continuam a ser aceites muitas das propostas metodológicas desenvolvidas no quadro da modernidade pedagógica, designadamente por via da Escola Nova, mas esvaziadas do projeto de transformação social que lhes estavam subjacentes. A "escola ativa" decorrente dessa reinterpretação surge como perfeitamente conciliável com as tradições católica e patriótica e, em particular, passível de ser concretizada no quadro de um regime autoritário (o Estado Novo) e de uma ideologia conservadora (o salazarismo). As disciplinas de Didática (Didática geral, em associação com a Pedagogia, e Didáticas especiais), herdeiras da pedagogia científica da transição para o século XX, aprimoram os seus procedimentos técnicos e a preocupação com o rigor do trabalho pedagógico, ao mesmo tempo que abraçam os valores de um projeto pedagógico que se procura legitimar na tradição ao mesmo tempo que recusa os valores da modernidade liberal.

A noção de "meio-termo", de alguma maneira presente em algumas das conceções já apresentadas, serve igualmente a Moreirinhas Pinheiro para definir aspetos importantes da sua pedagogia. Falando, por exemplo, da cópia diz-nos o autor: "Deve seguir-se o meiotermo. A cópia é, na verdade, um bom exercício para atingir fins caligráficos e ortográficos; o seu abuso pode levar, porém, a um automatismo pernicioso" (p.42). Idêntica opinião defende em relação à polémica sobre a importância das datas no ensino da história: "entre estas duas opiniões contraditórias deve o mestre seguir o meio-termo" (p.91).

De meio-termo se pode falar, na verdade, em relação à apropriação que autores e professores como Octávio Dordonnat, Moreirinhas Pinheiro, Orbelino Geraldes Ferreira, José Maria Gaspar ou Francisco de Sousa Loureiro fazem da herança da Escola Nova, combinando-a com a tradição da pedagogia católica. Os discursos são esvaziados das teses mais radicais e dos projetos de transformação social subjacentes a algumas das correntes do movimento, sendo enfatizada a sua dimensão técnico-científica.

A construção da disciplina de Didática Especial nos currículos da formação de professores é parte integrante desse sincretismo pedagógico. O lugar central por ela 
ocupado representa, igualmente, uma vontade de sedimentar uma certa tradição docente, vista como "arte de ensinar", e os rituais a ela associados, parcialmente decorrentes do "tato pedagógico" do mestre. À volta da Didática Especial reúne-se uma plêiade notável de educadores e de formadores de professores que constroem a sua identidade profissional tendo como referência o discurso didático, considerado especializado, e a fundamentação pedagógica compósita proveniente da Escola Nova na sua interpretação católica e conservadora. O campo das Didáticas permitiu a preservação de uma certa memória pedagógica, a construção de uma identidade disciplinar e o aprofundamento duma cultura profissional dos professores, em particular no que se refere ao então chamado ensino primário.

\section{Referências:}

GASPAR, J. M. \& FERREIRA, O. G. Notas de Didática Especial. Coimbra: Coimbra Editora, 1944.

LOUREIRO, F. S. Lições de Pedagogia e Didática Geral. Coimbra: Livraria Gonçalves, 1950

MOGARRO, M. J. Bibliotecas particulares e saberes pedagógicos: circulação e apropriação de modelos culturais. In: PINTASSILGO, J. et al. (Org.). História da escola em Portugal e no Brasil: circulação e apropriação de modelos culturais. Lisboa: Edições Colibri / Centro de Investigação em Educação da Faculdade de Ciências da Universidade de Lisboa, 2006, p.233-257.

MOGARRO, M. J. A formação de professores no Portugal contemporâneo. A Escola do Magistério Primário de Portalegre (Tese de Doutoramento). Cáceres: Universidad de Extremadura, 2001.

NÓVOA, A. (Dir.). Dicionário dos Educadores. Lisboa: Edições ASA, 2003, p. 297-298 e 334-336.

NÓVOA, A. Le Temps des Professeurs. Analyse socio-historique de la profession enseignante au Portugal (XVIIIe-XXe siècle). Lisboa: Instituto Nacional de Investigação Científica, 1987.

PINHEIRO, J. E. M. Elementos para um livro de memórias. Lisboa: [s.n.], 1996a.

PINHEIRO, J. E. M. Escritos vários relativos à Escola Normal Primária e à Escola do Magistério Primário de Lisboa. Lisboa: Escola Superior de Educação de Lisboa, 1996b.

PINHEIRO, J. E. M. Introdução ao estudo da Didática Especial, para uso dos alunosmestres das Escolas do Magistério Primário (2. edição, revista e aumentada). Lisboa: [s.n.], 1961.

PINTASSILGO, J. \& PEDRO, L. C. A disciplina de Didática Especial na Escola do Magistério Primário de Lisboa. O exemplo do Prof. Moreirinhas Pinheiro. In: Hernández Díaz, J. M. (Coord.). Formación de Élites y Educación Superior en Iberoamérica (ss. XVI - XXI). Salamanca: Hergar Ediciones Antema, 2012, Vol. II, p.241-251. 
PINTASSILGO, J. \& PEDRO, L. C. As disciplinas de Didática nas Escolas do Magistério Primário. Reflexões em torno do currículo da formação de professores. Comunicação apresentada ao XIX Colóquio da Secção Portuguesa da AFIRSE - Revisitar os Estudos Curriculares: onde estamos e para onde vamos? - realizado no Instituto de Educação da Universidade de Lisboa entre 2 e 4 de Fevereiro de 2012.

PINTASSIlGO, J., MOGARRO, M. J. \& HENRIQUES, R. P. A Formação de Professores em Portugal. Lisboa: Edições Colibri, 2010.

PINTASSILGO, J. \& SERRAZINA, L. (Org.). A Escola Normal de Lisboa e a Formação de Professores: arquivo, história e memória. Lisboa: Edições Colibri / Centro de Investigação em Educação / Escola Superior de Educação de Lisboa, 2009.

PORTUGAL. Diário do Governo, Decreto- lei n. ${ }^{\circ}$ 43369, 2 de dezembro de 1960.

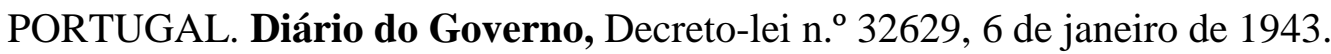

PORTUGAL. Diário do Governo, Decreto- lei n. ${ }^{\circ}$ 32243, 5 de Setembro de 1942.

TOLEDO, M. R. A. \& MOGARRO, M. J. Circulação e apropriação de modelos de leitura para professores no Brasil e em Portugal: Edições pedagógicas da Companhia Editora Nacional nas bibliotecas portuguesas». In M. M. C. Carvalho \& J. Pintassilgo (Orgs.). Modelos culturais, saberes pedagógicos, instituições educacionais: Portugal e Brasil, histórias conectadas. S. Paulo: EDUSP / FAPESP, 2011, pp.161-183.

\footnotetext{
${ }^{1}$ E-mail: japintassilgo@ie.ul.pt

${ }^{2}$ E-mail: lcpedro@ie.ul.pt

${ }^{3} \mathrm{O}$ presente texto retoma e aprofunda as ideias desenvolvidas pelos autores nas duas comunicações a seguir indicadas: Pintassilgo \& Pedro (2012a; 2012b). A pesquisa subjacente a este trabalho enquadra-se nas atividades do projeto Escolas de formação de professores em Portugal: história, arquivo, memória (20102012), financiado pela Fundação para a Ciência e a Tecnologia (FCT) e coordenado por Joaquim Pintassilgo.
}

Recebido em abril de 2012

Aprovado em maio de 2012 